\title{
Communication
}

\section{Testing the Obligations of Presence in Academia in the COVID-19 Era}

\author{
Clare Shelley-Egan
}

Work Research Institute, Oslo Metropolitan University, NO-0130 Oslo, Norway; clare.shelley-egan@oslomet.no

Received: 15 May 2020; Accepted: 5 August 2020; Published: 7 August 2020

\begin{abstract}
The COVID-19 crisis has given us a new, unprecedented impetus for thinking about the imperative of mobility in research. Travel and co-presence are widely accepted as being essential to career progression and promotion in academic life. Academics with fewer opportunities to travel find themselves at a significant disadvantage. COVID-19 and related public health measures have significantly limited the ability to be physically co-present in academia. Addressing obligations of co-presence in a less mobile world allows us to think concretely—and empathetically-about how to improve and extend virtual networking opportunities to those who have been marginalised with respect to research mobility. It also allows us to reflect on the role of reduced mobility and locality in how we think about and enact research. This article is informed and inspired by insights from research addressing academic mobility. I describe and discuss two prospects to productively work towards a new academic modus operandi characterised by limited opportunities for mobility. Furthermore, I highlight those issues and components that will require capacity building and a greater allocation of resources within the research system. In addition, I sketch out some pressing issues and questions for research mobility studies in a less mobile age going forward.
\end{abstract}

Keywords: COVID-19 pandemic; co-presence; academic modus operandi; reduced mobility; virtual technological solutions; equity; locality

\section{Introduction}

The COVID-19 crisis has given us a new impetus for thinking about the central place of mobility in the academic modus operandi, or the various practices that sustain academic work. Prior to the crisis, the (past) modus operandi could be characterised as reflecting an imperative for mobility in research. Mobility and physical proximity are distinctive features of academic life [1,2], with travel and co-presence accepted as being essential to career progression and promotion [3,4]. Researchers, research organisations, and research policy-makers have been engaged in a carbon-intensive working mode, fuelled by increasing expectations of international research cooperation and cheap air travel [5]. In addition to environmental impact, there are other impacts of the demand for mobility, such as unequal opportunity due to gender, career stage, caring responsibilities, disabilities, lack of resources, and geography $[1,5,6]$. Moreover, the mobility imperative has an effect on how academics generate and value knowledge, and on obligations and attachments to their particular locality [2]. A plethora of calls for a more sustainable research system have sprung up, along with discussion and analysis of technological solutions that would allow for "virtual mobility" [5,7-10]. A marked reduction in the "hypermobility" [11] seen in the research system—and associated negative environmental consequences-was viewed as being possible only through a paradigmatic shift in research culture $[5,6,12,13]$. A "denormalisation" of air travel would necessitate "a complex, systemic shift in how academics collaborate and communicate" [14] (p. 768).

Drastic changes have been wrought by the crisis. COVID-19 has negated our ability to be physically co-present in academia by virtue of severe public health measures at local, national, and transnational 
scales. In response to the COVID-19 pandemic outbreak and a host of social distancing measures, universities have been shut and researchers, students, and staff have been required to stay at home and work from a "home office". Lecturers have scrambled to move their courses online. With thousands of flights grounded and borders closed, researchers have also been grounded and a slew of planned conferences and meetings have either been rescheduled or moved entirely online [15,16]. Much desired changes in aeromobility in hyper-mobile sectors, such as academia, have been effected, not through anticipated plodding institutional change but in response to a major global public health emergency. The research community finds itself in a situation of reduced mobility and constrained opportunities for physical co-presence and face-to-face communication. The current instantiation of the academic modus operandi has thus manifested itself in remote working practices.

While there are certainly challenges in navigating this mode of doing research, there are also opportunities to capitalise on ongoing changes. We already see, for example, huge changes in air pollution levels as a positive consequence of the grounding of hypermobile travellers, such as researchers. More researchers than ever have access to a multitude of online webinars and conferences. Addressing obligations of physical co-presence in a less mobile world allows us to think concretelyand empathetically-about how to improve and extend virtual networking opportunities to those who have been marginalised with respect to research mobility. It also allows us to reflect on the role of reduced mobility in how we think about and enact research relative to our immediate contexts. Thus, along with the significant disruption and hardship this public health crisis has visited on our everyday lives, it also offers incentives for the research community to imagine, and actively design, a future academic modus operandi characterised by a more sustainable, equitable and societally relevant research system.

I describe and discuss two prospects to actualise a future academic modus operandi characterised by limited mobility. Each prospect takes its entrance point from past and current problematics of the imperative of research mobility (see above) and sets out ideas for the shape of a new modus operandi. For the first prospect-cultivating good virtual co-presence in a less mobile world-I propose concrete suggestions regarding possibilities for good virtual co-presence. Moreover, I highlight those issues and components that will require capacity building and the allocation of increased resources within the research system. The second prospect-reconfiguring research priorities and roles, with an emphasis on locality - operates at a more theoretical level, interrogating the implications of proximity for research ontology and epistemology. I sketch out some pressing issues and questions that could be taken forward in studies on research mobility/co-presence in a less mobile age. The focus in this article is on travel and co-presence for conferences and meetings-this is the type of co-presence that primarily features in literature on research mobility. The COVID-19 crisis has also focused attention on another type of co-presence-co-presence in terms of commuting to the office and daily physical presence at the office. Given the novel aspects of our current working situation, it is difficult not to engage at all with the latter kind of co-presence. Thus, I engage with the latter form of co-presence here only where it clearly converges with-and impacts upon-the former kind of co-presence. Finally, in the conclusion, I call for continued critical engagement with the possibilities for a new academic modus operandi in a less mobile, less networked time.

\section{Theoretical Resources: The New Mobilities Paradigm}

In order to develop an imagination of and practical suggestions for a future modus operandi for mobility in academia, an understanding of the work mobility of academics is needed. The theoretical resources informing this paper derive from scholarship that addresses academic mobility. The field of mobilities research concerns the study of mobilities as objects of study that warrant "extended attention" [17] (p. 3). The "new mobilities" paradigm that emerged over a decade and a half ago highlights a "style of analysis' in which mobilities are treated critically and in context" (ibid, p. 3). Certain trajectories of theoretical development can be observed and are relevant here. One important theoretical contribution is the focus on the social aspects of mobility and the importance of creating 
networks. This highlights the importance of the "social" in travel [18], with face-to-face proximity and social activities viewed as key constituents of much of social life, both formal and informal3. Social life is "networked", requiring "meetingness" [19] or specific co-present meetings within specific times and places. Another related theoretical contribution for this article is the emphasis on the importance of power relations and differential capacity for mobility [20]. Aspects of mobilities are political and they are implicated in the production of power and relations of domination [21]. For example, the mobilities of some might be enhanced in particular contexts, times, and places, while, at the same time, the immobilities of others are reinforced [22]. Finally, mobilities research foregrounds the importance of material foundations, such as virtual communication systems in sustaining "long distance working lives organized across borders" [23] (p. 235). Networks can be said to "(...) depend greatly on both an infrastructure of communication systems and a big technical system of aeromobility" (p. 235).

Within this theoretical framing, I seek to call attention to prospects for a new modus operandi characterised not only by fewer opportunities for physical co-presence but also possibilities for a more equitable research system, and a more localised embedding of research and researchers. Insights into the social impetus of research mobility, differential capacity for mobility, and the importance of virtual communication systems in sustaining networks are critical to understanding what is at stake on occasions of curtailed or blocked mobility. These insights open up prospects for a recalibration of the academic modus operandi, as I set out in the next section.

\section{Towards Actualising a New Academic Modus Operandi}

\subsection{Prospect 1: Cultivating Good Virtual Co-Presence in a Less Mobile Era}

\subsubsection{The Importance of Physical Co-Presence in Academia}

The "obligations of co-presence" [3,19] play a crucial role in academic culture, collaboration, and networking and the dissemination of research. Such obligations underline "(...) the importance of the human body and its materialities and mobilities in practices of meeting in the global workplace" [24] (p. 595). Proximity and "meetingness" are important to academia, as a form of social life [18]; thick co-presence facilitates access to the eyes, turn taking within conversations, and an expectation of mutual attentiveness. The specific forms of social life, in which academic practices are embedded, can be described as "networked sociality" [19]. Network sociality is founded on flows of information, the exchange of data, the sharing of ideas, and "catching up" [25]. Physical co-presence also allows for gossip and serendipitous moments [19,25].

\subsubsection{Current Problematics: Variation in the Capacity to Be Mobile}

Notwithstanding the salience of academic mobilities in research life and progression, it is widely acknowledged that the "practice of academic mobilities is not evenly distributed or experienced" [6] (p. 472). Variations in the capacity to travel/be co-present occur across gender, disability, caring responsibilities, career stage, employment status, geography, and fear of flying $[1,6,26])$. The politics of mobility is a key issue addressed by various scholars $[6,11,21]$, highlighting " $(. .$.$) the ways in which$ mobilities are both productive of social relations and produced by them" [21] (p. 21). Academics with caring responsibilities, e.g., family or other dependents, and especially women caring for young children, will be particularly challenged in their capacity for mobility [2]. Even if gender issues are put to one side, anyone attached to a certain locality for specific reasons will be constrained in their ability to respond to mobility demands [2]. The geographical remoteness of research actors and organisations also serves to restrict capacity and opportunities for mobility [26]. Australian and New Zealand academics, for example, wrestle with the "tyranny of distance" [6] (p. 475), with many Australian academics reporting that they experience a major disadvantage with respect to opportunities for research collaboration, compared to researchers in the Northern Hemisphere [26]. The situation is 
further complicated by the "incongruence of academic rhythms" between the Northern and Southern hemispheres, which can lead to the exclusion of some academics [6] (p. 479), e.g., Northern Hemisphere summer conferences often take place during busy teaching periods in the Southern Hemisphere. The "politics of conference funding" [27] poses another challenge, affecting academics on short-term contracts and students and researchers in resource-poor parts of the world; such individuals are compromised in their capacity to travel and to avail of networking and conference opportunities.

This crisis also makes us cognisant of the nature and role of de facto immobilities—and associated divisions of labour-that function to sustain the research system. These divisions and roles have always existed-and, perhaps, been taken for granted-but have been highlighted by this crisis. When it became clear that universities would have to close, ordinarily immobile actors such as university administration, human resource personnel, and IT personnel played a crucial role in facilitating the swift and smooth transfer of physical work and virtual systems from the university office to the home office. COVID-19 has also highlighted the precarity of-largely immobile-individuals within fixed-term, teaching only, early career academic positions. In ordinary times, these individuals are often kept grounded by a lack of conference funding, additional teaching obligations, service responsibilities, and so on. In the so-called "corona times", hundreds of university staff on precarious contracts in UK universities have been dismissed by their employers in a push to slash costs as a result of the pandemic [28]. This extraordinary situation can, thus, also serve to focus attention on the roles and personnel both enabled and constrained by immobility. With respect to the latter group, the move online and switch to communication platforms and tools has actually created greater precarisation [29] in this time of disruption.

\subsubsection{Possibilities for Change}

With respect to geographical remoteness, an enforced lack of academic mobility could serve to ameliorate the "tyranny of distance" by levelling the playfield for many more researchers, regardless of jurisdiction, and facilitating virtual access to conference and networking opportunities-the coming months will be insightful in this regard. On a practical level, research organisations and universities will make savings on traditional conferences and reduced travel; such savings can be diverted back to departments and research labs, enabling a greater number of individual researchers to have enhanced access to knowledge and networking opportunities [30]. Being grounded may also allow academics without children or caring responsibilities-individuals who may often be asked or expected to travel more frequently than others due to their "unburdened" status-to achieve a healthier balance in their travel commitments [31]. However, increased access to resource-poor individuals may remain a significant challenge.

In terms of future research directions, Urry's [18] notion of mobilities and the "good life" offers an interesting perspective on how we might positively respond to and harness some of these sudden changes to our working lives towards a fairer politics of mobility and "good" co-presence. According to Urry, the "good society" would "(...) would seek to extend the possibilities of co-presence to every social group and regard infringements of this as involving undesirable social exclusion" (p. 270). This is not only because co-presence is desirable in its own right but also because face-to-face meetings broaden social capital and promote economic activity in "mutually self-sustaining ways". Elsewhere, Urry's [19] notion of the "good life 'lived-at-a-distance'" (p. 171) —which he defines as "meetingness through co-present bodies" — can be repurposed to align with our current situation and needs. Limitations on physical co-presence and proximity allow us to imagine another kind of good society or good life lived-at-a-distance, designed, crucially, around the many and not the few. For instance, how might researchers reconfigure their role and abilities to modify their social and network capital in the absence of physical co-presence? The "coerced immobilities" [18] referred to above force us to reflect further on the kinds of change and contingency planning required to mitigate the unequal consequences of the pandemic within the research system (i.e., increased precarity of temporary, teaching-only positions). At the same time, we need to cultivate and maintain opportunities for connectedness and knowledge 
exchange for those previously excluded from the advantages of physical co-presence by virtue of the availability of resources, geographical context, etc. Virtual conferences and events can "raise the bar" for greater inclusivity and diversity in research by increasing the diversity of speakers and adjusting for variations between researchers with fewer resources and at different career stages [32].

One crucial component of a good life lived-at-a-distance is the availability of effective technological alternatives that can enable "virtual-travel practices" [23]. Indeed, a plethora of technological alternatives already exists [5]. Crucially, such alternatives have been developed in parallel with face-to-face meetings, underlining the synergistic link of virtual technologies with travel [25]. Indeed, prior to the COVID-19 crisis, the growing capacity for virtual substitution in the form of technological alternatives had not diminished academic air travel $[8,23,25]$ - on the contrary. Instead, virtual substitution was viewed as a supplement to air travel rather than as a substitute [3]. Such substitution functions in cases in which networks, collaborations, and relationships already exist but fails in enabling the thick co-presence and intense personal interaction viewed as integral to maintaining networks and relationships [3,25].

This supplementary position is now undermined by the lack of opportunity to travel as a complement to online interactions. While this may be the case only in the short to medium term, our intensified engagement with virtual forms of communication allows us to evaluate and plan for how they could be improved in a potentially less mobile world going forward. In terms of future research, the efficiency and efficacy of technological solutions is certainly important, not only in terms of technical functionality [5], but also with respect to effects on collaboration and career progression opportunities $[28,32,33]$. The benefits of online alternatives compared to physical attendance/presence include the ability to attract contributions from a wider audience and to provide access to multiple sources of information; lower maintenance work in making connections; the broader dissemination and promotion of one's work; and the removal of not only financial costs but also time and personal costs [5]. Moreover, virtual conferences demonstrate specific benefits, such as pre- and post-conference activity (making presentations and other content available before and after the conference) [33,34]; and real-time feedback using chat functions [35].

\subsubsection{Remaining Challenges}

Until now, these benefits have remained largely theoretical and untested, and at a remove from the actual use and uptake of such solutions. A concerted effort is needed to couple (and promote) the actual benefits with the functionalities of the virtual solutions; the communication needs of our current working lives allow us to make this step in a less ad hoc manner. On the whole, there is a lack of information regarding virtual conferences, their number, implementation, audiences, quality, and influence [36]. In the last two or three years, and most recently in the spring and early summer of 2020, there has been increased engagement by researchers and conference organisers with the opportunities of virtual conferencing. In addition to descriptions of good practices, attention has been paid to the specific dynamics of planning for virtual conferences (e.g., the roles of hosts and moderators, the selection of appropriate technology, and the importance of backup possibilities such as pre-recorded sessions) $[37,38]$. Successful experiences with the implementation of virtual conferences have also been reported in the literature [28,32,33,35,39-41], with concrete ideas for virtual conferences ranging from virtual poster sessions, to pre-recorded talks with question and answer sessions, and the early dissemination of research through pre-prints made available online. Much has already been achieved in formulating and trying out virtual events in academia. At the same time, given the sudden and hastily planned move online precipitated by the COVID-19 crisis, researchers should not expect online conferences to run perfectly, at least in the short term [36].

There is still considerable scope for innovation in replicating or enhancing the experience of traditional conferences [33,38]. In particular, social events are "Arguably the most integral part of providing a high-fidelity virtual conference" [39]. Homing in further, there is a need for a tighter coupling between the technical and the social needs and imperatives of research life. In the corona era, 
we have seen the adaptation of Zoom calls, for example, to more informal co-presence moments and occasions, such as cocktail hours, birthday parties, and even wedding parties. We can gain inspiration from these occasions to think about how the nature of virtual co-presence in the workplace might be modified and improved to facilitate more "organic" and free-flowing communication. For instance, can we "manufacture" those moments of serendipity that play such an integral role in face-to-face meetings such as conferences? Research has shown that there are concrete ways of developing the conditions for serendipity, e.g., the creation of agile structures and processes such as IT platforms and random pairings of people who have not met [42]. Researchers need to develop the capacity and "muscle" for serendipity and seizing opportunities as they arise, making the most of the adaptability of technological solutions and digital tools.

Additional major, and pressing, challenges for a new, virtual modus operandi relate to the fact that people need fast internet connections in order to meaningfully participate in virtual events and that some communication protocols are blocked by some nations [38]. Even if internet access is available, the bandwidth needed for virtual conferences may not suffice [43]. This is clearly not a problem that can be overcome by any individual conference organiser or university alone; rather it necessitates action and resource allocation at a national level [44]. Nonetheless, this particular gap in access to information and knowledge requires acknowledgement and thoughtful planning on the part of virtual event organisers; for example, in their article on how to run big neuroscience conferences online, Goodman et al. [38] report that those with poor connections can access better videos from YouTube.

Returning to organisational levels, universities will need additional and more dedicated technical support in order to optimise technological solutions. IT designers and experts might collaborate with researchers to identify their needs and co-create solutions. Accounting and administrative personnel will need to establish a support infrastructure to ensure the provision of locally available, high-quality video or teleconferencing facilities [5]. Institutional and funding incentives-aimed at "normalising" the extended use of virtual communication going forward-will require some thought. Inspiration can be taken from proposals for climate-friendly research that centre on the inclusion of ecological considerations in funding criteria (replacing face-to-face meetings with conference calls), for example [45].

\subsection{Prospect 2: An Emphasis on Locality: Reconfiguring Research Priorities and Roles}

\subsubsection{Current Problematics: The Imposition of Research Travel and the Neglect of Domestic Contexts}

Curtailed mobility as a result of the pandemic - via the grounding of aeromobility practices-also allows us to consider-and even embrace-new ways of relating to research priorities and to our roles as researchers in specific, localised contexts. Research investigating the bodily and emotional experiences of academic mobilities [6] is relevant here. Hopkins et al. encounter the notion of "efficient travel", defined as getting as much done as possible and returning from a trip exhausted. Short-term efficiency in the context of academic travel involves "discourses of healthiness, capability (skills and bodily), and freedom from "things" (e.g., bags, mobility aids) and "people" (e.g., children)" (p. 477). This short-term efficiency leads to longer-term "inefficiencies", extending into the weeks following travel, while also present in planning and coordination before travel. These findings, the authors suggest, serve to underline the salience of-and sacrifices made for-academic travel: "Such findings signal the complexities of reducing work-related mobilities where our participants tolerate often extreme bodily, emotional and social impacts because of the perceived importance of travel" (p. 477). In a similar vein, Ciers et al. [46] note that the time and energy invested in travelling, along with related jetlag and fatigue, could compromise overall professional performance and quality of life. Time is a precious commodity in the research world; a reduction in participation in international conferences can free up time to work on one's research in a more dedicated fashion. Indeed, almost two decades ago, Høyer and Næss [47] questioned whether conferences—and in particular, large and prestigious conferences-live up to the expectation of enhancing professional and scientific understanding: "Could 
it be hoped, then, that the scientific and professional impulses from the conference will contribute to a substantial increase in the quality of the small amount of research that it is possible to get done within the limited time available?" (p. 465).

Another relevant issue concerns an "ethics of the body", i.e., questions concerning care, generosity, and relationality that stem from the body and are situated in a specific context [2]. Parker and Weik [2] suggest that an ethics of the body is marginalised by institutions that "demand that bodies are placed at their disposal" and that "the comportment and disposition of human resources is a strategic and not an ethical question" (p. 178). This form of marginalisation, in turn, causes the disembodiment of the employee, which can lead to disembodied thinking and acting. Such a thought shifts the focus away from immediate questions of care and relationality to academic problems prioritised by universities, such as "gap spotting, abstracted empiricism and the generation of widely disseminated theoretical implications" ( $p$ 178): "These are the forms of frictionless thought that are encouraged by the academy, and that academics can package easily and take on aeroplanes, publish in journals and get grants to work on." Conversely, "Accounts of local or parochial responsibilities, of "sticky" encounters with the world and of specific forms of care and engagement are less likely to travel well." (p. 178).

\subsubsection{Possibilities for Change}

In the COVID-19 era, matters of care and obligations to one's family (and one's community and fellow citizens) have assumed centre stage. The COVID-19 experience allows us to reconceive of an "ethics of the body" situated in a space dominated by relational and caring priorities. In a longer-term perspective, this might generate new methodologies and new social research framings underpinned by the demands and conditions of our less mobile lives. New approaches to conceptualising and conducting research can make our research more relevant and bring us closer to society and to our local communities. Looking ahead in the coming months and years, we may see greater emphasis on local conferences and dissemination events. Prior to this crisis, scholars observed the diminishment of local conferences at the expense of international conferences, which tend to bring in greater revenue for university campuses and to the coffers of academic associations and societies [1]. Local conferences also tend to be disparaged as less "prestigious" and "impactful" than international conferences [7,48]. A new or reinvigorated focus on the local can enhance the connections of researchers to their local societies and cultures and the issues that both sustain and challenge such communities [47].

The ontology of what it is to be a researcher and the temporalities, role identities, methodologies and epistemologies tied up with that will, most likely, adopt a different hue in -and beyond-this crisis. One particular area in which major change may occur, going forward, is international travel for conferences and meetings, which is both time and energy intensive. The current dearth of physical mobility may serve to focus attention on the questionable aspects of efficiency in academic work, e.g., extensive travel to deliver a 15 min presentation in a busy, anonymous hotel conference room. Our increased engagement with technological solutions may also spur us on to be more efficient in how we prioritise, organise, and conduct our meetings. For example, a number of commentaries have been written recently about how tiring Zoom meetings can be due to the absence of those features that make face-to-face meetings more stimulating and easier to negotiate, i.e., non-verbal communication, receptiveness, and so on [48]. Considerations regarding whether such virtual meetings are necessary or can be replaced by phone or e-mail could be taken forward to our return to the office.

\subsubsection{Future Research Directions}

We can also interrogate the impacts of proximity on our identities as researchers: What are the implications when our researcher role identities and other role identities (parent, carer, partner) co-exist in an extreme form of proximity? Finally, we can think about how proximity might influence how we think about and deliver research. What kinds of frictions does proximity introduce? (How) can we work with and productively mobilise these frictions? What kinds of new avenues of thought and research might proximity open up? Interrogating these kinds of questions will require new empirical 
insights and conceptual innovation regarding efficiency and performance in research, and an ethics of the body situated in a more local context, informed by priorities of care and domestic responsibilities.

\section{Conclusions}

The COVID-19 crisis—albeit a public health catastrophe for many nations and individuals—offers an opportunity for positive change across many sectors of society, including the research sector. In a matter of days and weeks, COVID-19 and the public health response to it effected major change in how we think about and enact research communication and dissemination. The crisis has laid bare the machinery of the research system, including the mobility imperative. Reduced mobility has brought into relief the mobility imperative of the research system but has also offered an occasion on which to reflect on the possibilities for another modus operandi, characterised by a more sustainable, equitable, and societally relevant research system. This article has homed in on two prospects that might allow us to confront and come to terms with past and current mobility aspects of the academic modus operandi, and to constructively pursue a new academic modus operandi in which the physical obligations of co-presence will be more difficult to meet. Insights regarding the features of good physical co-presence can be adapted and extended to the virtual sphere. Cultivating good virtual co-presence pushes us to think about how the good life lived-at-a-distance can be facilitated for the many, and not just the few. The current situation allows us to identify and actively seek out openings to be more inclusive of those normally constrained by distance, caring responsibilities, and so on. Moreover, we now have an opportunity to engage-in a targeted way - with the technical aspects and solutions of our new working lives. At organisational levels, allowances for-and concrete resources-must be made available for the necessary technical supports and infrastructures to be implemented. The COVID-19 crisis has also foregrounded issues of care and relationality within the academic work context. In ordinary, mobile times, domestic and caring priorities and responsibilities tend to be overlooked-at least at a systemic level—in the push for efficiency in work-related mobilities, which, in turn, has led to a sort of decontextualised disembodiment of the travelling academic. In addition, there has been a kind of disconnect from locality and the issues that drive localities. The grounding of academics allows for an invigorated focus on the local and offers possibilities for the research community to engage with, and prioritise, issues that drive and concern their immediate communities. Furthermore, limitations on mobility offer an opportunity to reflect on the impacts of proximity on our identities and roles as researchers, and on how we formulate and implement research.

The COVID-19 pandemic has acted as a catalyst for reflection on the obligations of physical co-presence in academia. We have an occasion now to harness our experiences of radically reduced mobility and new modes of visibility and to re-imagine entrenched cultural practices. It appears that the virus may be with us for some time to come and so we need to continue to be adaptable and resilient. In a longer-term perspective, the climate crisis and concerns about the environmental impact of hyper-mobile travellers will continue to be a key driving force in discussions and policy initiatives around research mobility. Indeed, mobilities research and sustainability research advancing climate change action have paved the way for critical engagement with the kind of research system we want in our current socio-technical context. We-research scholars, administrators, and managers alike-have a responsibility now to share the mantle, consolidate synergies between the climate crisis and the COVID-19 crisis, and move both practices and the research agenda forward. It would be a shame to waste this opportunity. To use a phrase from the COVID-19 lexicon, it may be time for a "new normal".

Funding: This research was funded by the Work Research Institute at Oslo Metropolitan University.

Acknowledgments: I gratefully acknowledge important suggestions for the paper from Cathrine Egeland and Desmond Treacy. I am also grateful to the anonymous reviewers for their constructive feedback.

Conflicts of Interest: The author declares no conflict of interest. 


\section{References}

1. Ackers, M. Internationalisation, Mobility and Metrics: A New Form of Indirect Discrimination? Minerva 2008, 46, 411-435. [CrossRef]

2. Parker, M.; Weik, E. Free spirits? The academic on the aeroplane. Manag. Learn 2014, 45, 167-181. [CrossRef]

3. Storme, T.; Faulconbridge, J.R.; Beaverstock, J.V.; Derudder, B.; Witlox, F. Mobility and Professional Networks in Academia: An Exploration of the Obligations of Presence. Mobilities 2017, 12, 405-424. [CrossRef]

4. Nursey-Bray, M.; Palmer, R.; Meyer-Mclean, B.; Wanner, T.; Birzer, C. The Fear of Not Flying: Achieving Sustainable Academic Plane Travel in Higher Education Based on Insights from South Australia. Sustainability 2019, 11, 2694. [CrossRef]

5. Le Quéré, C.; Capstick, S.; Corner, A.; Cutting, D.; Johnson, M.; Minns, A.; Schroeder, H.; Walker-Springett, K.; Whitmarsh, L.; Wood, R. Towards a Culture of Low-Carbon Research for the 21st Century. Tyndall Working Paper 161, March 2015. Available online: https:/tyndall.ac.uk/publications/tyndall-working-paper/2015/ towards-culture-low-carbon-research-21st-century (accessed on 1 April 2020).

6. Hopkins, D.; Higham, J.; Orchiston, C.; Duncan, T. Practising academic mobilities: Bodies, networks and institutional rhythms. Geogr. J. 2019, 185, 472-484. [CrossRef]

7. Cohen, S.; Hanna, P.; Higham, J.; Hopkins, D.; Orchiston, C. Gender discourses in academic mobility. Gender Work Organ. 2020. [CrossRef]

8. Glover, A.; Strengers, Y.; Lewis, T. The unsustainability of academic aeromobility in Australian universities. Sustain. Sci. Pract. Policy 2017, 13, 1-12. [CrossRef]

9. Caset, F.; Boussauw, K.; Storme, T. Meet \& fly: Sustainable transport academics and the elephant in the room. J. Transp. Geogr. 2018, 70, 64-67.

10. Hamant, O.; Saunders, T.; Viasnoff, V. Cele brate sustainable travel at conferences. Nature 2019, 573, 451-452. [CrossRef]

11. Cohen, S.A.; Gossling, S. A darker side of hypermobility. Environ. Plan. D 2015, 47, 1661-1679. [CrossRef]

12. Waring, T.; Teisl, M.; Manandhar, E.; Anderson, M. On the Travel Emissions of Sustainability Science Research. Sustainability 2014, 6, 2718-2735. [CrossRef]

13. Higham, J.; Font, X. Decarbonising academia: Confronting our climate hypocrisy. J. Sustain. Tour. 2020, 28, 1-9. [CrossRef]

14. Glover, A.; Strengers, Y.; Lewis, T. Sustainability and academic air travel in Australian universities. Int. J. Sustain. High. Educ. 2018, 19, 756-772. [CrossRef]

15. Viglione, G. A year without conferences? How the Coronavirus pandemic could change research. Nature 2020, 579, 327-329. [CrossRef]

16. Service, R.F. Coronavirus epidemic snarls science worldwide. Science 2020, 367, 836-837. [CrossRef]

17. Faulconbridge, J.; Hui, A. Traces of a Mobile Field: Ten Years of Mobilities Research. Mobilities 2016, 11, 1-14. [CrossRef]

18. Urry, J. Mobility and Proximity. Sociology 2002, 36, 255-274. [CrossRef]

19. Urry, J. Social networks, travel and talk. Br. J. Sociol. 2003, 54, 155-175. [CrossRef]

20. Sheller, M. Mobility. Sociopedia. Isa. 2011. [CrossRef]

21. Cresswell, T. Towards a politics of mobility. Environ. Plan. D 2010, 28, 17-31. [CrossRef]

22. Sheller, M.; Urry, J. The mobilities paradigm. Environ. Plan. D 2006, 38, 207-226. [CrossRef]

23. Lassen, C. Networking, knowledge organizations and aeromobility. 2009. Geogr. Ann. Ser. B Hum. Geogr. 2009, 91, 229-243. [CrossRef]

24. Strengers, Y. Meeting in the Global Workplace: Air Travel, Telepresence and the Body. Mobilities 2015, 10, 592-608. [CrossRef]

25. Higham, J.E.S.; Hopkins, D.; Orchiston, C. The work-sociology of academic aeromobility at remote institutions. Mobilities 2019, 14, 612-631. [CrossRef]

26. Glover, A.; Lewis, T.; Strengers, Y. Overcoming remoteness: The necessity of air travel in Australian universities. Aust. Geogr. 2019, 50. [CrossRef]

27. Hopkins, D.; Higham, J.; Tapp, S.; Duncan, T. Academic mobility in the Anthropocene era: A comparative study of university policy at three New Zealand institutions. J. Sustain. Tour. 2016, 23, 376-397. [CrossRef]

28. Weissgerber, T.; Bediako, Y.; de Winde, C.M.; Ebrahimi, H.; Fernandez-Chiappe, F.; Ilangovan, V.; Tay, A. Mitigating the impact of conference and travel cancellations on researchers' futures. eLife 2020, 9, e57032. [CrossRef] 
29. Storme, T.; Beaverstock, J.V.; Derudder, B.; Faulconbridge, J.R.; Witlox, F. How to cope with mobility expectations in academia: Individual strategies of tenured academics at Ghent University, Flanders. Res. Transp. Bus. Manag. 2013, 9, 12-20. [CrossRef]

30. Batty, D. Hundreds of University Staff to be Made Redundant Due to Coronavirus. The Guardian. 2 April 2020. Available online: https:/www.theguardian.com/education/2020/apr/02/hundreds-of-university-staffmade-redundant-due-to-coronavirus (accessed on 29 April 2020).

31. Woodcock, J. Digital Labour in the University: Understanding the Transformations of Academic Work in the UK. tripleC 2018, 16, 129-142. [CrossRef]

32. Sarabipour, S.; Schewessinger, B.; Mumoki, F.N.; Mwakilili, A.D.; Khan, A.; Debat, H.J.; Sáez, P.J.; Seah, S.; Mestrovic, T. Evaluting features of scientific conferences: A call for improvements. BioRxiv 2020. [CrossRef]

33. Achakulvisut, T.; Ruangrong, T.; Bilgin, I.; van den Bossche, S.; Wyble, B.; Goodman, D.F.; Kording, K.P. Improving on legacy conferences by moving online. eLife 2020, 9. [CrossRef] [PubMed]

34. Weller, M. The Digital Scholar: How Technology is Transforming Scholarly Practice; Bloomsbury Academic: London, UK, 2011.

35. Woolston, C. Learning to love virtual conferences. Nature 2020, 582, 135-136. [CrossRef] [PubMed]

36. Sá José, M.; Ferreira, C.M.; Serpa, S. Virtual and Face-To-Face Academic Conferences: Comparison and Potentials. J. Educ.Soc. Res. 2019, 9. [CrossRef]

37. Diethart, M.; Zimmermann, A.B.; Mulà, I. Guidelines for Virtual Conferencing-Inspired by the Copernicus Alliance Online Conference 2019; CDE and COPERNICUS Alliance: Bern, Switzerland, 2020. Available online: https://www.copernicus-alliance.org/images/Downloads/CA_Guidelines_for_Virtual_Conferencing web.pdf (accessed on 5 June 2020).

38. Goodman, D.; Wyble, B.; Achakulvisut, T.; Bilgin, I.; Van den Bossche, S.; Kording, K. How to Run Big Neuroscience Conferences Online-Neuromatch.io. Medium, 2020. Available online: https://medium.com/ @kording/how-to-run-big-neuro-science-conferences-online-neuromatch-io-49c694c7e65d (accessed on 5 June 2020).

39. Rubinger, L.; Gazendam, A.; Ekhtiari, S.; Nucci, N.; Payne, A.; Johal, H.; Bhandari, M. Maximizing virutal meetings and conferences: A review of best practices. Int. Orthop. 2020. [CrossRef]

40. Haage, V. A survey of travel behaviour among scientists in Germany and the potential for change. eLife 2020, 9, e56765. [CrossRef]

41. Fraser, H.; Soanes, K.; Jones, S.A.; Jones, C.S.; Malishev, M. The value of virtual conferencing for ecology and conservation. Conserv. Biol. 2017, 31, 540-546. [CrossRef]

42. World Forum. How to Make the Most of Serendipity at Work. Available online: https://www.weforum.org/ agenda/2018/07/how-to-make-serendipity-happen-at-work/ (accessed on 29 April 2020).

43. Oester, S.; Cigliano, J.A.; Hind-Ozan, E.J.; Parsons, E.C.M. Why Conferences Matter-An Illustration from the International Marine Conservation Congress. Front. Mar. Sci. 2017, 4. [CrossRef]

44. Bohannon, J. Who is getting left behing in the internet revolution? Science 2016, 9, aah7284. [CrossRef]

45. Kirchhoff, T.; Getzinger, G.; Helgenberger, S.; Pawloff, A.; Röthler, D.; Schmitz, D.; Zagel, B. Climate Friendly Climate Research Policy Brief “Feasibility Assessment”. JPI CLIMATE-Climate Friendly Climate Research Project, 2014. Available online: http://www.jpi-climate.eu/media/default.aspx/emma/org/10850052/ JPI_Alliance_CFCR+Policy+Brief_Feasibility+Assessment_1.pdf (accessed on 1 April 2020).

46. Ciers, J.; Mandic, A.; Toth, L.D.; Op't Veld, G. Carbon Footprint of Academic Air Travel: A Case Study in Switzerland. Sustainability 2019, 11, 80. [CrossRef]

47. Høyer, K.G.; Naess, P. Conference Tourism: A Problem for the Environment, as well as for Research? J. Sustain. Tour. 2001, 9, 451-470. [CrossRef]

48. Sander, L.; Bauman, O. 5 Reasons Why Zoom Meetings Are So Exhausting. The Conversation. 5 May 2020. Available online: https://theconversation.com/5-reasons-why-zoom-meetings-are-so-exhausting-137404 (accessed on 6 May 2020).

(C) 2020 by the author. Licensee MDPI, Basel, Switzerland. This article is an open access article distributed under the terms and conditions of the Creative Commons Attribution (CC BY) license (http://creativecommons.org/licenses/by/4.0/). 